\title{
Oxidative stress enhances the expression of sulfur assimilation genes: preliminary insights on the Enterococcus faecalis iron-sulfur cluster machinery regulation
}

\author{
Gustavo Pelicioli Riboldi', Christine Garcia Bierhals², Eduardo Preusser de Mattos ${ }^{3}$, \\ Ana Paula Guedes Frazzon², Pedro Alves d’Azevedo', Jeverson Frazzon ${ }^{4}+$ \\ ${ }^{1}$ Laboratório de Cocos Gram-positivos e Microbiologia Molecular, Departamento de Microbiologia, Universidade Federal de Ciências da \\ Saúde de Porto Alegre, Porto Alegre, RS, Brasil ${ }^{2}$ Programa de Pós-Graduação em Microbiologia Agrária e do Ambiente, \\ Departamento de Microbiologia ${ }^{3}$ Programa de Pós-Graduação em Genética e Biologia Molecular \\ ${ }^{4}$ Instituto de Ciência e Tecnologia de Alimentos, Universidade Federal do Rio Grande do Sul, Porto Alegre, RS, Brasil
}

\begin{abstract}
The Firmicutes bacteria participate extensively in virulence and pathological processes. Enterococcus faecalis is a commensal microorganism; however, it is also a pathogenic bacterium mainly associated with nosocomial infections in immunocompromised patients. Iron-sulfur [Fe-S] clusters are inorganic prosthetic groups involved in diverse biological processes, whose in vivo formation requires several specific protein machineries. Escherichia coli is one of the most frequently studied microorganisms regarding [Fe-S] cluster biogenesis and encodes the iron-sulfur cluster and sulfur assimilation systems. In Firmicutes species, a unique operon composed of the sufCDSUB genes is responsible for [Fe-S] cluster biogenesis. The aim of this study was to investigate the potential of the $\mathrm{E}$. faecalis sufCDSUB system in the [Fe-S] cluster assembly using oxidative stress and iron depletion as adverse growth conditions. Quantitative real-time polymerase chain reaction demonstrated, for the first time, that Gram-positive bacteria possess an OxyR component responsive to oxidative stress conditions, as fully described for $\mathrm{E}$. coli models. Likewise, strong expression of the sufCDSUB genes was observed in low concentrations of hydrogen peroxide, indicating that the lowest concentration of oxygen free radicals inside cells, known to be highly damaging to [Fe-S] clusters, is sufficient to trigger the transcriptional machinery for prompt replacement of [Fe-S] clusters.
\end{abstract}

Key words: suf operon - [Fe-S] cluster assembly - Firmicutes - oxidative stress - iron depletion

Iron-sulfur ([Fe-S]) clusters are ubiquitous inorganic prosthetic groups involved in biological processes as diverse as electron transfer, redox and non-redox catalysis and gene regulation (Frazzon \& Dean 2003, Lill 2009). Although [Fe-S] clusters are easily assembled in vitro from elementary $\mathrm{Fe}^{2+/ 3+}$ and $\mathrm{S}^{2-}$ in a reductive environment (Malkin \& Rabinowitz 1966, Kiley \& Beinert 2003), this process in vivo requires several specific protein machineries.

[Fe-S] cluster assembly and delivery are most frequently studied in Proteobacteria, for which three types of biosynthetic machineries have been described: nitrogen fixation $(N I F)$, iron-sulfur cluster (ISC) and sulfur assimilation (SUF). The NIF system was first described in Azotobacter vinelandii and comprises structural and regulatory genes specialised in maturation of nitrogenase and NIF (Jacobson et al. 1989a, b, Rubio \& Ludden 2008). The $I S C$ system, highly conserved in Proteobacteria, is encoded by the iscRSUA-hscBA-fdx operon and represents the housekeeping genes for $\mathrm{Fe} / \mathrm{S}$ protein maturation (Zheng et al. 1998). Lastly, the sufABCDSE

doi: 10.1590/0074-0276140006

Financial support: CNPq (302471/2009-0, 470388-2009-9,

473769/2007-7), CAPES PDEE Institucional (23038007207201144)

+Corresponding author: jeverson.frazzon@ufrgs.br

Received 8 January 2014

Accepted 27 March 2014 operon encoded by the $S U F$ system plays a key role in growth under stressful conditions, such as oxidative and nitric oxide stresses and iron starvation (Takahashi \& Tokumoto 2002, Fontecave et al. 2005). Four well-characterised SUF regulators have already been described, namely, Fur and the oxidant-responsive (ORE) activators I, II and III, which correspond to the proteins OxyR, IHF and IscR, respectively (Py \& Barras 2010). Likewise, cis-interacting elements for these regulators have been characterised in Escherichia coli (Lee et al. 2004) (Fig. 1). The transcriptional repressor and global regulator of cellular iron, Fur and the activator complex IscR-OxyRIHF compete for the same promoter region of the sufABCDSE operon (Guerinot 1994, Hantke 2001, Schwartz et al. 2001, Outten et al. 2004), thus tightly controlling the expression of SUF genes.

The Firmicutes phylum corresponds to a group of bacteria that extensively participates in human virulence and pathological processes. Enterococcus faecalis is a commensal microorganism that colonises the mammalian gastrointestinal tract; however, it is also a pathogenic bacterium, mainly associated with nosocomial infections in immunocompromised patients (Fisher \& Phillips 2009), such as urinary tract, wound, bloodstream and endocardium infections (Sava et al. 2010). E. faecalis virulence is mainly due to factors related to adherence and invasion of host tissues, immunomodulation, toxin-mediated damage and resistance to a wide range of antimicrobial agents (Arias et al. 2010). 
Oxidative stress and iron depletion are common cellular challenges faced by E. faecalis upon host invasion (Caza \& Kronstad 2013, Winterbourn \& Kettle 2013), which suggests an important role for the SUF system in pathogenesis. Firmicutes species encode a genetic cluster for [Fe-S] cluster assembly, which is mostly composed of E. coli SUF homologues (sufC, sufD, sufS, sufB) and an additional suf $U$ gene, as well as an E. coli isc $U$ orthologue (Riboldi et al. 2009). Recently, the demonstration of complementation in trans of E. coli sufABCDSE by the E. faecalis sufCDSUB suggested a degree of similarity between these machineries (Riboldi et al. 2011). Additionally, the E. faecalis SUF gene cluster seems to be transcribed as an operon and potential regulatory cis-elements homologous to E. coli Fur, IHF and OxyRbinding sequences were identified within the $E$. faecalis $S U F$ promoter region (Fig. 1, Supplementary data).

Considering the high degree of conservation of the $S U F$ system in Firmicutes, the sole presence of the sufCDSUB operon in E. faecalis and the fact that iron depletion and cellular oxidative stress are linked to the regulation of the SUF machinery in well-characterised organisms, the aim of this study was to investigate the potential of the E. faecalis sufCDSUB system in [Fe-S] cluster assembly, using oxidative stress and iron depletion as adverse growing conditions.

\section{MATERIALS AND METHODS}

Strains and media - E. faecalis strain ATCC 51299 (Swenson et al. 1995), here referred to as strain X1, which corresponds to a vancomycin-resistant and clinically relevant strain isolated from peritoneal fluid during a clinical outbreak, was used in this study. Two other E. faecalis strains were used to confirm the results obtained with the X1 strain. These are the widely used and well-characterised laboratory strains FA22 (Jacob et al. 1975) and JH22 (Yagi \& Clewell 1980). Cultures were performed with brain heart infusion (BHI) broth and/or media. Vancomycin was used when necessary at a final concentration of $30 \mu \mathrm{g} / \mathrm{mL}$.
Hydrogen peroxide $\left(\mathrm{H}_{2} \mathrm{O}_{2}\right)$ and 2',2'-dipyridyl (DIP) challenge conditions - E. faecalis strains were grown to an optical density at $600 \mathrm{~nm}$ of 0.5 , harvested by centrifugation and suspended in $0.9 \%(\mathrm{w} / \mathrm{v}) \mathrm{NaCl}$ in the following concentrations of $\mathrm{H}_{2} \mathrm{O}_{2}: 2.0 \mathrm{mM}, 5.0 \mathrm{mM}, 10.0 \mathrm{mM}, 20.0$ $\mathrm{mM}, 30.0$ and $40.0 \mathrm{mM}$. Cultures were incubated at $37^{\circ} \mathrm{C}$ in a water bath for $30 \mathrm{~min}$ and the RNA was subsequently extracted. Iron starvation was induced by the addition of $0.2 \mathrm{mM}, 0.4 \mathrm{mM}, 0.6 \mathrm{mM}, 0.8 \mathrm{mM}$ or $1 \mathrm{mM}$ to BHI-broth prior to the incubation of the cultures at $37^{\circ} \mathrm{C}$.

Quantitative real-time polymerase chain reaction $(q P C R)$ procedures - Total RNA was isolated from exponentially growing control and stressed cells, using a CTAB-modified protocol (Salter \& Conlon 2007). Two micrograms of total RNA were used for cDNA synthesis using the M-MLV reverse transcriptase (Promega) and random hexamer and/or oligo-dT primers (Invitrogen). E. faecalis V583 reference sequences for primer design for sufC (GenBank EF2394), sufD (EF2393), sufS (EF2392), sufU (EF2391), sufB (EF2390), kat (EF1597), fur (EF1525), oxyR (EF2958), 23S rRNA (EF23SD), elongation factor for transporter RNA (tuf) (EF0201), RNA polymerase beta chain $(r p o B)(\mathrm{EF} 3238)$ and gyrase beta chain $(g y r B)(E F 0005)$ were obtained from the Institute for Genomic Research (tigr.org). qPCR was performed in an ABI-7500 (Applied Biosystems) thermal cycler using 96-well plates and SYBR green (Bio-Rad) as a dye. Expression levels of $r p o B, g y r B$, tuf and $23 \mathrm{~S}$ ribosomal RNA (23SrRNA) were evaluated as possible reference controls for data normalisation. The specific linear behaviour of these candidate genes was analysed carefully (see below). PCR conditions were as follows: an initial denaturation step at $95^{\circ} \mathrm{C}$ for $3 \mathrm{~min}$ followed by 45 cycles at $95^{\circ} \mathrm{C}$ for 15 $\mathrm{s}$ and $58^{\circ} \mathrm{C}$ for $45 \mathrm{~s}$. Melting curves were estimated by the application of an additional step that increased the temperature of the samples from $70-95^{\circ} \mathrm{C}\left(1^{\circ} \mathrm{C} \mathrm{min}^{-1}\right)$.

Data analysis - Data analyses were performed using the comparative critical threshold $\left({ }^{\Delta \Delta} \mathrm{Ct}\right)$ method (Livak $\&$ Schmittgen 2001). Relative expression levels of strains

\section{E. coli}

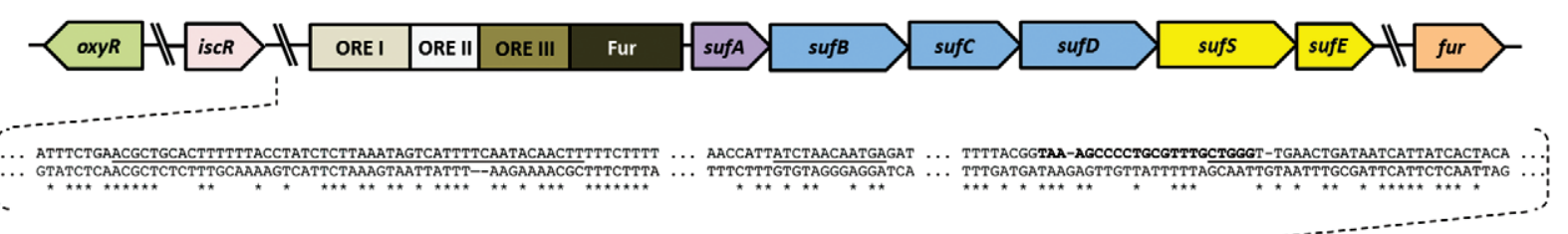

E. faecalis

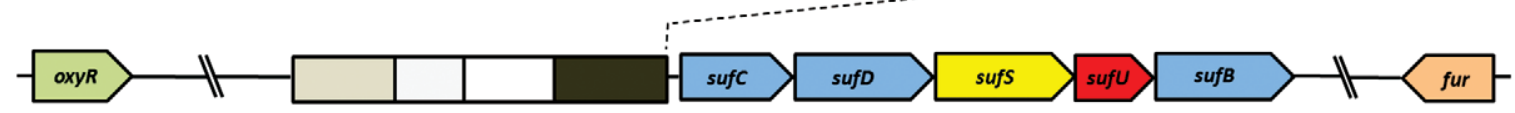

Fig. 1: molecular machinery for the biosynthesis of $S U F$ [Fe-S] clusters in Escherichia coli and Enterococcus faecalis and the genomic localisation of Fur, OxyR and IscR regulators. Genes and cis-element regions with similar functions and/or orthologous sequences are depicted by the same colours. The boxes represent promoter-associated cis-elements for OxyR [oxidant-responsive (ORE) I], IHF (ORE II), IscR (ORE III) and Fur binding. The inset shows a pair-wise DNA alignment of $E$. coli and $E$. faecalis promoter regions. Underlined sequences, from left to right, correspond to the ORE I, ORE II and Fur elements, respectively, while the DNA region depicted in bold corresponds to the ORE III cis-element. 

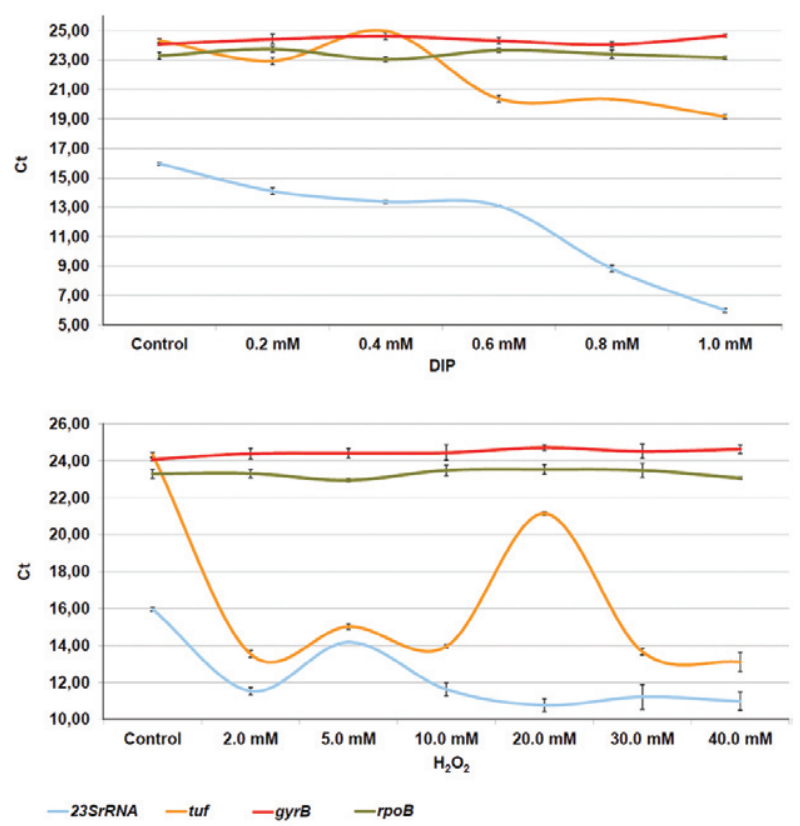

Fig. 2: critical threshold $(\mathrm{Ct})$ values for quantitative polymerase chain reaction of gyrase beta chain $(\operatorname{gyr} B)$, RNA polymerase beta chain (rpoB), elongation factor for transporter RNA $(t u f)$ and 23S ribosomal RNA (23SrRNA) genes of Enterococcus faecalis strain X1 under different simulations of iron depletion (left panel) and oxidative stress (right panel). DIP: 2',2'-dipyridyl; $\mathrm{H}_{2} \mathrm{O}_{2}$ : hydrogen peroxide.

from the control group were calculated in the same way, only discriminating 0 as the value for ${ }^{\Delta} \mathrm{Ct}_{\text {stress condition }}$ during the process of ${ }^{\Delta \Delta} \mathrm{Ct}$ determination. The $\mathrm{ABI} 7500$ Real-Time PCR SDS Software v.2.0 was used to analyse thresholds and baselines of individual transcriptional profiles. An internal control was determined using the same method. Experiments were performed in biological triplicate and experimental quadruplicate. The constitutive genes were carefully considered to identify the optimal normalisation gene among the set of candidates by the three following algorithms: NormFinder (Andersen et al. 2004), geNorm (Vandesompele et al. 2002) and BestKeeper (Pfaffl et al. 2004). qPCR results were analysed through one-way ANOVA using the SAS software package and results presenting $p<0.05$ were considered statistically significant.

\section{RESULTS}

Relative expression of the SUF operon: finding appropriate housekeeping genes for data normalisation - In an attempt to find good constitutive gene candidates for our qPCR measurements, we determined the expression profile of $r p o B, g y r B$, tuf and 23SrRNA under the different growth conditions studied here. As illustrated in Fig. 2 , the linearity observed for the $\operatorname{gyr} B$ and $r p o B$ genes was satisfactory, with a minor variation of $1 \mathrm{Ct}$ among the different cellular growth conditions. However, $t u f$ and 23SrRNA did not exhibit a regular expression pattern, as verified by the wide $\mathrm{Ct}$ ranges observed under the various conditions. Additionally, in silico analysis of these candidate constitutive genes using the algorithms Normfinder,
geNorm and BestKeeper predicted gyrB and rpoB to be the most stably expressed genes for data normalisation. Similar experiments with E. faecalis FA22 and JH22 strains corroborated these results (Supplementary data).

Oxidative stress enhances sufCDSUB expression dramatically - To study the expression pattern of the E. faecalis SUF operon under challenging conditions, cultures were subjected to oxidative stress by being exposed to increasing quantities of $\mathrm{H}_{2} \mathrm{O}_{2}$ and were separately grown under iron limitation with increasing concentrations of the iron chelator, DIP. As demonstrated in Fig. 3, qPCR revealed extremely negative ${ }^{\Delta \Delta} \mathrm{Ct}$ values for all $\mathrm{H}_{2} \mathrm{O}_{2}$ concentrations tested. These values were statistically significant when compared to the control group and indicated a substantial transcriptional increase of these genes, as illustrated by relative gene expression $\left(2^{-\Delta \Delta C t}\right)$ in the heat-map shown in Fig. 4. kat, a gene whose expression pattern is indicative of oxidative stress, was included in the experiment as a positive control to indicate this growth challenge. As expected, kat expression levels were up regulated in all conditions tested, which confirmed that the cells were under oxidative stress. The sufCDSUB genes showed a significant transcriptional induction in all $\mathrm{H}_{2} \mathrm{O}_{2}$ concentrations tested, with an up to 10,000 -fold increase in gene expression, when compared to control growth conditions (Fig. 4).

The $\operatorname{oxy} R$ gene was included in this study after identification of a putative $\operatorname{oxy} R$ regulatory region in the $E$. faecalis genome similar to the characteristic cis-acting responsive element for oxidative stress previously verified in E. coli (Supplementary data). Thus, to analyse the putative connection between OxyR and the transcription of the sufCDSUB operon, the expression pattern of $\operatorname{oxy} R$ was also quantified. As expected, upon exposure to $\mathrm{H}_{2} \mathrm{O}_{2}$ the relative expression of $\operatorname{oxy} R$ was significantly enhanced (Figs 3, 4). Importantly, the expression profiles obtained for the E. faecalis X1 strain were similar to those obtained for the FA22 and JH22 strains (Supplementary data), reinforcing the data presented here.

The challenge of iron-limiting environments - Iron limitation resulted in the least conclusive data, because little effect on $S U F$ expression was observed in lower concentrations of DIP. However, an increase in the transcriptional activation of sufCDSUB could be clearly identified when $0.6 \mathrm{mM}$ DIP was added to the growth medium (Fig. 4). It seems that the $E$. faecalis $S U F$ operon experiences a decrease in its expression pattern when exposed to increasing iron chelator concentrations, as verified upon exposure to $0.8 \mathrm{mM}$ and $1.0 \mathrm{mM} \mathrm{DIP}$; however, an enhancement in $\operatorname{sufCDSUB}$ expression was still notable. This same DIP-concentration-dependent decrease in the transcriptional activation of SUF could be observed when the data were normalised relative to both the constitutive gyrB and rpoB genes (Figs 3, 4). kat and oxyR showed the same expression pattern, with the highest activation in $0.6 \mathrm{mM}$ DIP and subsequent transcriptional decay in increasing concentrations of DIP. Transcription of $s u f B$ behaved in an unusual manner, reaching a 10 -fold transcriptional induction under $0.2 \mathrm{mM}$ DIP; notwithstanding, this signal was lost when data were normalised 

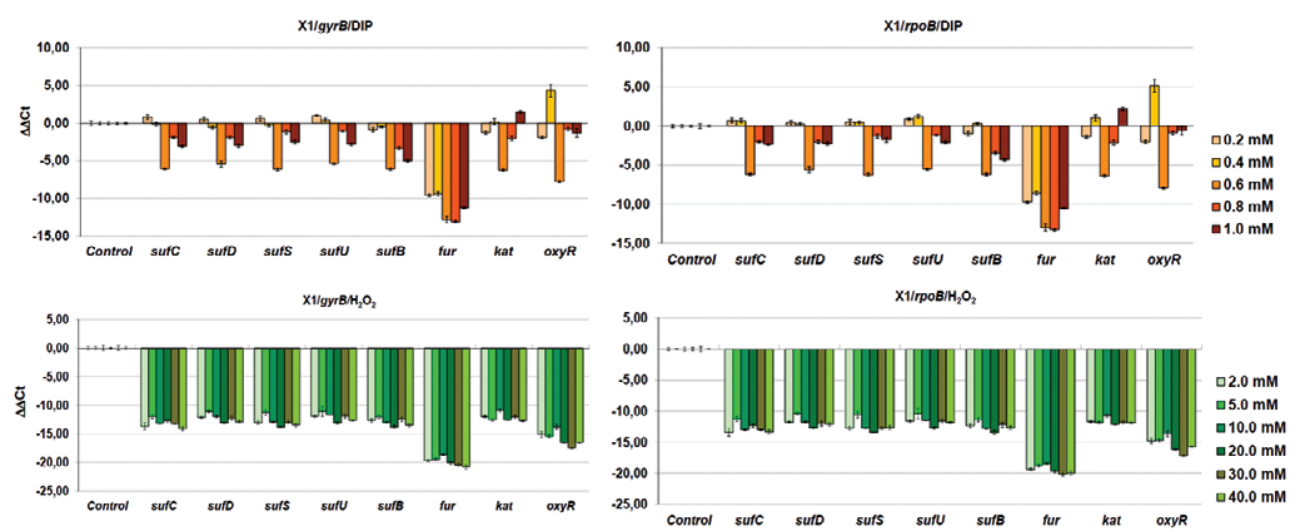

Fig. 3: comparative critical threshold $\left({ }^{\Delta \Delta} \mathrm{Ct}\right)$ data after normalisation relative to the expression profiles of the constitutive genes gyrase beta chain $(g y r B)$ (upper and lower left panels) or RNA polymerase beta chain (rpoB) (upper and lower right panels). Graphics represent experiments performed with the Enterococcus faecalis X1 strain upon increasing conditions of iron depletion [2',2'-dipyridyl (DIP): 0.2-1.0 mM; upper left and right panels] or oxidative stress [hydrogen peroxide $\left(\mathrm{H}_{2} \mathrm{O}_{2}\right): 2.0-40 \mathrm{mM}$; lower left and right panels]. Error bars are also included to indicate data variance.

relative to $g y r B$ expression (Fig. 4). Transcription of fur showed more than a 1,000-fold increase in gene expression under all concentrations of DIP tested and these results remained highly significant after normalisation to both of the constitutive genes used. However, the pattern of fur expression verified for the X1 strain was not reproduced in the FA22 and JH22 strains.

\section{DISCUSSION}

This paper describes the transcriptional pattern of genes related to the [Fe-S] cluster assembly in E. faecalis cells under oxidative stress and iron depletion conditions. Basic bioinformatics analyses enabled us to identify regions in the sufCDSUB promoter region that are similar to the E. coli $S U F$ system cis-elements involved in the binding of the regulators OxyR (ORE I), IHF (ORE II) and Fur.

In an attempt to further characterise the E. faecalis SUF system, the present work demonstrated a concomitant response of sufCDSUB and its putative transcriptional modulators, oxyR and fur, because $\operatorname{sufCDSUB}$ upregulation always followed an increase in the expression of both regulators. Recently, the viability of $E$. coli double mutants of the $I S C$ and $S U F$ systems that encoded the sufCDSUB gene cluster from $E$. faecalis was described, indicating that the $S U F$ systems from both bacteria might act in a similar manner in vivo (Riboldi et al. 2011). The data presented here suggest a similar type of regulation for the SUF systems of both Proteobacteria and Firmicutes, highlighting an additional degree of homology between both $E$. coli and E. faecalis SUF systems. Differences in the expression patterns among the $E$. faecalis strains used here could be due to the genetic diversity of Enterococcus isolates obtained from different niches (Vebø et al. 2010), because the X1 strain was originally isolated from a blood infection (most likely presenting a more invasive phenotype), whereas both FA22 and JH22 are laboratory standardised strains. Further experiments are needed to achieve a consistent conclusion about iron depletion and its relation to the $\operatorname{sufCDSUB}[\mathrm{Fe}-\mathrm{S}]$ cluster assembly machinery.

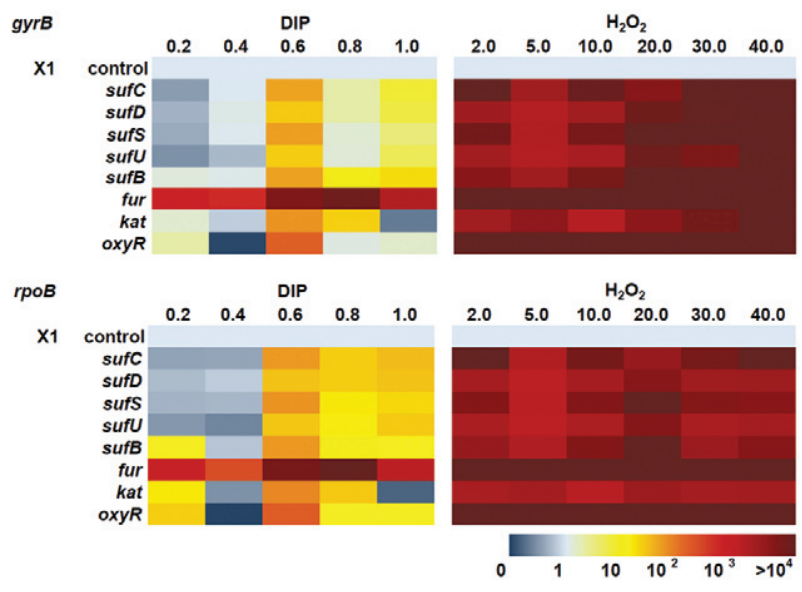

Fig. 4: general relative gene expression patterns $\left(2^{-\Delta \Delta C t}\right)$ of $\operatorname{sufCDSUB}$, fur, kat and $\operatorname{oxy} R$ genes normalised relative to the expression profile of the constitutive genes gyrase beta chain $($ gyr $B)$ (upper left and right panels) or RNA polymerase beta chain (rpoB) (lower left and right pannels) for the E. faecalis X1 strain. Challenging cellular conditions included increasing conditions of iron depletion [2',2'-dipyridyl (DIP): 0.2-1.0 mM; upper and lower left panels] and oxidative stress [hydrogen peroxide $\left(\mathrm{H}_{2} \mathrm{O}_{2}\right): 2.0-40 \mathrm{mM}$; upper and lower right panels]. Colours relate to the degree of relative gene expression from absent (blue) to high expression (dark red), as depicted in the label.

Pathogens have evolved complex iron acquisition and oxidative stress response mechanisms to survive and establish infections. Microbial virulence phenotypes have already been associated with the [Fe-S] cluster machinery, as well as with Fur and OxyR regulators and their respective cis-elements, which are involved in the regulation of microbial pathogenicity and are important in overcoming host defence mechanisms during both the infection and colonisation processes. Fur is a regulator of the iron uptake and transport systems (Clarke et al. 2001), inhibiting the expression of its targets upon iron binding and thus ensuring the cellular iron homeostasis. For instance, Fur is required for the expression of Staphylococcus aureus virulence determinants, such as 
cytolysin and immunomodulatory proteins and for protection against host neutrophils (Johnson et al. 2011). Additionally, Fur has been reported to play a role in the virulence of Bacillus cereus (Newton et al. 2005), Listeria monocytogenes (Harvie et al. 2005) and Streptococcus suis (Aranda et al. 2010).

In a similar manner, OxyR has been attributed a role in the virulence processes of $E$. coli (Johnson et al. 2006), Porphyromonas gingivalis (Wu et al. 2008) and Bacteroides fragilis (Sund et al. 2008). Moreover, OxyR is associated with Pseudomonas aeruginosa resistance to human neutrophils (Lau et al. 2005) and the secretion of potent cytotoxic factors (Melstrom Jr et al. 2007). The host colonisation processes in Klebsiella pneumoniae (Hennequin \& Forestier 2009) and Xylella fastidiosa (Toledo et al. 2011) have also been linked to OxyR, which may also be involved in antimicrobial resistance, because its inactivation was shown to increase Mycobacterium tuberculosis sensitivity to isonicotinic acid hydrazide (Pagán-Ramos et al. 2006). The wellcharacterised interaction between OxyR and Fur upon cellular stress could explain the constant association of transcriptional induction between both Fur and OxyR elements verified here.

Because E. faecalis is a potentially pathogenic bacterium, the data described here suggest the presence of $S U F$ regulators and cis-elements similar to those characterised in E. coli may contribute to the understanding of the virulence mechanisms employed by this microorganism. Accordingly, our results support involvement of the $\operatorname{sufCDSUB}$ machinery and its putative regulatory elements Fur and OxyR in E. faecalis infectivity, host immune defence evasion and/or colonisation processes, as has been observed for the maintenance of the bacterium redox balance through the activity of lactate dehydrogenase (LDH) (Rana et al. 2013). Those authors demonstrated that LDH is crucial for E. faecalis infectivity and resistance to several environmental stresses, such as exposure to $\mathrm{H}_{2} \mathrm{O}_{2}$. Likewise, E. faecalis could potentially be relying on the $S U F$ system to maintain an additional level of protection against host defence mechanisms and this hypothesis prompts further investigation.

In summary, the work presented here describes innovative data related to the expression of the E. faecalis sufCDSUB biosynthetic machinery involved in [Fe-S] clusters assembly. Moreover, the $S U F$ genes are shown to be transcriptionally up-regulated upon exposure to cellular oxidative stress.

\section{ACKNOWLEDGEMENTS}

To Prof Rogério Margis, for contributions related to qPCR data analyses.

\section{REFERENCES}

Andersen CL, Ledet-Jensen J, Ørntoft T 2004. Normalization of realtime quantitative RT-PCR data: a model based variance estimation approach to identify genes suited for normalization - applied to bladder and colon-cancer data-sets. Cancer Res 64: 5245-5250.

Aranda J, Garrido ME, Fittipaldi N, Cortés P, Llagostera M, Gottschalk M, Barbé J 2010. The cation-uptake regulators AdcR and Fur are necessary for full virulence of Streptococcus suis. Vet Microbiol 144: 246-249.
Arias CA, Contreras GA, Murray BE 2010. Management of multidrug-resistant enterococcal infections. Clin Microbiol Infect 16: $555-562$.

Caza M, Kronstad JW 2013. Shared and distinct mechanisms of iron acquisition by bacterial and fungal pathogens of humans. Front Cell Infect Microbiol 19: 80.

Clarke TE, Tari LW, Vogel HJ 2001. Structural biology of bacterial iron uptake systems. Curr Top Med Chem 1: 7-30.

Dam P, Olman V, Harris K, Su Z, Xu Y 2007. Operon prediction using both genome-specific and general genomic information. Nucleic Acids Res 35: 288-298.

Dehal PS, Joachimiak MP, Price MN, Bates JT, Baumohl JK, Chivian D, Friedland GD, Huang KH, Keller K, Novichkov PS, Dubchak IL, Alm EJ, Arkin AP 2009. MicrobesOnline: an integrated portal for comparative and functional genomics. Nucleic Acids Res 38: D396-D400.

Fisher K, Phillips C 2009. The ecology, epidemiology and virulence of Enterococcus. Microbiol 155: 1749-1757.

Fontecave M, Choudens SO, Py B, Barras F 2005. Mechanisms of iron-sulfur cluster assembly: the SUF machinery. $J$ Biol Inorg Chem 10: 713-721.

Frazzon J, Dean DR 2003. Formation of iron-sulfur clusters in bacteria: an emerging field in bioinorganic chemistry. Curr Opin Chem Biol 7: 166-173.

Guerinot ML 1994. Microbial iron transport. Anпи Rev Microbiol 48: $743-772$.

Hantke K 2001. Iron and metal regulation in bacteria. Curr Opin Microbiol 4: 172-177.

Harvie DR, Vílchez S, Steggles JR, Ellar DJ 2005. Bacillus cereus Fur regulates iron metabolism and is required for full virulence. Microbiology 151: 569-577.

Hennequin C, Forestier C 2009. OxyR, a LysR-type regulator involved in Klebsiella pneumoniae mucosal and abiotic colonization. Infect Immun 77: 5449-5457.

Hiard S, Marée R, Colson S, Hoskisson PA, Titgemeyer F, van Wezel GP, Joris B, Wehenkel L, Rigali S 2007. PREDetector: a new tool to identify regulatory elements in bacterial genomes. Biochem Biophys Res Commun 15: 861-864.

Jacob AE, Douglas GJ, Hobbs SJ 1975. Self-transferable plasmids determining the hemolysin and bacteriocin of Streptococcus faecalis var. zymogenes. J Bacteriol 121: 863-872.

Jacobson MR, Brigle KE, Bennett L, Setterquist RA, Wilson MS, Cash VL, Beynon J, Newton WE, Dean D 1989a. Physical and genetic map of the Major nif gene cluster from Azotobacter vinelandii. J Bacteriol 171: 1017-1027.

Jacobson MR, Cash VL, Weiss MC, Laird NF, Newton WE, Dean DR 1989b. Biochemical and genetic analysis of the nifUSVWZM cluster from Azotobacter vinelandii. Mol Gen Genet 219: 49-57.

Johnson JR, Clabots C, Rosen H 2006. Effect of inactivation of the global oxidative stress regulator $\operatorname{oxy} R$ on the colonization ability of Escherichia coli O1:K1:H7 in a mouse model of ascending urinary tract infection. Infect Immun 74: 461-468.

Johnson M, Sengupta M, Purves J, Tarrant E, Williams PH, Cockayne A, Muthaiyan A, Stephenson R, Ledala N, Wilkinson BJ, Jayaswal RK, Morrissey JA 2011. Fur is required for the activation of virulence gene expression through the induction of the sae regulatory system in Staphylococcus aureus. Int J Med Microbiol 301: 44-52.

Kiley PJ, Beinert H 2003. The role of Fe-S proteins in sensing and regulation in bacteria. Curr Opin Microbiol 6: 181-185. 
Lau GW, Britigan BE, Hassett DJ 2005. Pseudomonas aeruginosa OxyR is required for full virulence in rodent and insect models of infection and for resistance to human neutrophils. Infect Immun 73: 2550-2553

Lee JH, Yeo WS, Roe JH 2004. Induction of the sufA operon encoding $\mathrm{Fe}-\mathrm{S}$ assembly proteins by superoxide generators and hydrogen peroxide: involvement of OxyR, IHF and an unidentified oxidantresponsive factor. Mol Microbiol 51: 1745-1755.

Lill R 2009. Function and biogenesis of iron-sulphur proteins. Nature 460: $831-838$

Livak KJ, Schmittgen TD 2001. Analysis of relative gene expression data using real-time quantitative PCR and the $2^{\Delta \Delta \mathrm{Ct}}$ method. Methods 25: 402-408.

Malkin R, Rabinowitz JC 1966. The reconstitution of clostridial ferredoxin. Biochem Biophys Res Commun 23: 822-827.

Melstrom Jr KA, Kozlowski R, Hassett DJ, Suzuki H, Bates DM, Gamelli RL, Shankar R 2007. Cytotoxicity of Pseudomonas secreted exotoxins requires OxyR expression. J Surg Res 143: 50-57.

Newton SM, Klebba PE, Raynaud C, Shao Y, Jiang X, Dubail I, Archer C, Frehel C, Charbit A 2005. The svpA-srtB locus of Listeria monocytogenes: fur-mediated iron regulation and effect on virulence. Mol Microbiol 55: 927-940.

Outten FW, Djaman O, Storz G 2004. A suf operon requirement for Fe-S cluster assembly during iron starvation in Escherichia coli. Mol Microbiol 52: 861-872.

Pagán-Ramos E, Master SS, Pritchett CL, Reimschuessel R, Trucksis M, Timmins GS, Deretic V 2006. Molecular and physiological effects of mycobacterial oxyR inactivation. J Bacteriol 188: 2674 2680 .

Pfaffl MA, Tichopád A, Prgomet C, Neuvians TP 2004. Determination of stable housekeeping genes, differentially regulated target genes and sample integrity: BestKeeper-Excel-based tool using pair-wise correlations. Biotechnol Lett 26: 509-515.

Py B, Barras F 2010. Building Fe-S proteins: bacterial strategies. Nat Rev Microbiol 8: 436-446.

Rana NF, Sauvageot N, Laplace J-M, Bao YY, Nes I, Rincé A, Posteraro B, Sanguinetti M, Hartke A 2013. Redox balance via lactate dehydrogenase is important for multiple stress resistance and virulence in Enterococcus faecalis. Infect Immun 81: 2662-2668.

Riboldi GP, Larson TJ, Frazzon J 2011. Enterococcus faecalis sufCDSUB complements Escherichia coli sufABCDSE. FEMS Microbiol Lett 320: 15-24.

Riboldi GP, Oliveira JS, Frazzon J 2011. Enterococcus faecalis SufU scaffold protein enhances SufS desulfurase activity by acquiring sulfur from its conserved cysteine-153. Biochim Biophys Acta 1814: 1910-1918.

Riboldi GP, Verli H, Frazzon J 2009. Structural studies of the Enterococcus faecalis SufU [Fe-S] cluster protein. BMC Biochem 2: 10-13.
Rubio LM, Ludden PW 2008. Biosynthesis of the iron-molybdenum cofactor of nitrogenase. Annu Rev Microbiol 62: 93-111.

Salter MG, Conlon HE 2007. Extraction of plant RNA. Methods Mol Biol 62: 309-314.

Sava IG, Heikens E, Huebner J 2010. Pathogenesis and immunity in enterococcal infections. Clin Microbiol Infect 16: 533-540.

Schwartz CJ, Giel JL, Patschkowski T, Luther C, Ruzicka FJ, Beinert H, Kiley PJ 2001. IscR, an Fe-S cluster-containing transcription factor, represses expression of Escherichia coli genes encoding Fe-S cluster assembly proteins. Proc Natl Acad Sci USA 98: 14895-14900.

Sund CJ, Rocha ER, Tzianabos AO, Wells WG, Gee JM, Reott MA, O'Rourke DP, Smith CJ 2008. The Bacteroides fragilis transcriptome response to oxygen and $\mathrm{H}_{2} \mathrm{O}_{2}$ : the role of OxyR and its effect on survival and virulence. Mol Microbiol 67: 129-142.

Swenson JM, Clark NC, Sahm DF, Ferraro MJ, Doern G, Hindler J, Jorgensen JH, Pfaller MA, Reller LB, Weinstein MP 1995. Molecular characterization and multilaboratory evaluation of Enterococcus faecalis ATCC 51299 for quality control of screening tests for vancomycin and high-level aminoglycoside resistance in enterococci. J Clin Microbiol 33: 3019-3021.

Takahashi Y, Tokumoto U 2002. A third bacterial system for the assembly of iron-sulfur clusters with homologs in archea and plastids. J Biol Chem 277: 28380-28383.

Toledo MA, Schneider DR, Azzoni AR, Favaro MT, Pelloso AC, Santos CA, Saraiva AM, Souza AP 2011. Characterization of an oxidative stress response regulator, homologous to Escherichia coli OxyR, from the phytopathogen Xylella fastidiosa. Protein Expr Purif 75: 204-210.

Vandesompele J, de Preter K, Pattyn F, Poppe B, Van Roy N, de Paepe A, Speleman F 2002. Accurate normalization of real-time quantitative RT-PCR data by geometric averaging of multiple internal control genes. Genome Biol 3: PMID: 12184808

Vebø HC, Solheim M, Snipen L, Nes IF, Brede DA 2010. Comparative genomic analysis of pathogenic and probiotic Enterococcus faecalis isolates and their transcriptional responses to growth in human urine. PLOS ONE 5: e12489.

Winterbourn CC, Kettle AJ 2013. Redox reactions and microbial killing in the neutrophil phagosome. Antioxid Redox Signal 18: 642-660.

Wu J, Lin X, Xie H 2008. OxyR is involved in coordinate regulation of expression of fimA and sod genes in Porphyromonas gingivalis. FEMS Microbiol Lett 282: 188-195.

Yagi Y, Clewell DB 1980. Recombination-deficient mutant of Streptococcus faecalis. J Bacteriol 143: 966-970.

Zheng L, Cash VL, Flint DH, Dean DR 1998. Assembly of iron sulfur clusters: identification of an iscSUA-hscBA-fdx gene cluster from Azotobacter vinelandii. J Biol Chem 273: 13264-13272. 